\title{
Magnetotelluric evidences of metal rich fluid pathways in the Tapajós Mineral Province
} Raphael Teixeira Correa*12 ${ }^{*}$ Roberta Mary Vidotti², Sérgio Luiz Fontes ${ }^{3}$, Marcelo Lacerda Vásquez ${ }^{1}$ and Jaime Estevão Scandolara', ${ }^{1}$ Serviço Geológico do Brasil - CPRM, ${ }^{2}$ Universidade de Brasília, ${ }^{3}$ Observatório Nacional

Copyright 2021, SBGf - Sociedade Brasileira de Geofísica.

This paper was prepared for presentation during the $17^{\text {th }}$ International Congress of the Brazilian Geophysical Society held in Rio de Janeiro, Brazil, 16-19 August 2021.

Contents of this paper were reviewed by the Technical Committee of the $17^{\text {th }}$ International Congress of the Brazilian Geophysical Society and do not necessarily represent any position of the SBGf, its officers or members. Electronic reproduction or storage of any part of this paper for commercial purposes without the written consent of the Brazilian Geophysical Society is prohibited.

\begin{abstract}
The Tapajós Mineral Province (TMP) is a relevant gold producer in Brazil, for producing at least $750 \mathrm{t}$ in the last decades. Its evolution is related to ocean-continent orogenies from 2.1 to $1.87 \mathrm{Ga}$. The tectonic setting is still controversial since there are no high pressure and low-temperature terrains; neither classic fold and thrust belts are mapped. We propose to address the electrical structure of the TMP through magnetotelluric (MT) data. A $160 \mathrm{~km}$ profile MT field survey was conducted in the known Gold dirty road (Transgarimpeira). Resistivity images of the crust have been used to map crustal-scale discontinuities related to fossil fluid flows. We present the first electrical model for the lithosphere of TMP. We identified a major thrust fault juxtaposing two distinct crustal levels. Moreover, we mapped fluid pathways on the MT resistivity model with noticeable correlation with gold mineral deposits. A deep conductor around $12 \mathrm{~km}$ in the crust may be the evidence of past bulky melt volume. The MT data have provided relevant constraints to misunderstood structures presented on surface and magnetic data. It has also proved to be valued on detecting fluid pathways relevant for unraveling new mineral deposits.
\end{abstract}

